\title{
Grasshopper diversity in several agricultural areas and savannas in Dompu, Sumbawa Island, Indonesia
}

\author{
AMIN SETYO LEKSONO ${ }^{1, \boldsymbol{v}}$, BAGYO YANUWIADI ${ }^{1}$, AINUL KHOTIMAH ${ }^{1}$, ANISA ZAIRINA ${ }^{2}$ \\ ${ }^{1}$ Department of Biology, Faculty of Mathematics and Natural Sciences, Universitas Brawijaya. Jl. Veteran, Malang 65145, East Java, Indonesia. \\ Tel./fax.: +62-341- 551611, •email: amin28@ub.ac.id \\ ${ }^{2}$ Program of Forestry, Faculty of Forestry, Institut Pertanian Malang. Jl. Soekarno-Hatta, Malang 65141, East Java, Indonesia
}

Manuscript received: 10 November 2021. Revision accepted: 11 December 2021

\begin{abstract}
Leksono AS, Yanuwiadi B, Khotimah A, Zairina A. 2021. Grasshopper diversity in several agricultural areas and savannas in Dompu, Sumbawa Island, Indonesia. Biodiversitas 23: 75-80. In Sumbawa Island, the conversion of forests and savannahs into agricultural land has increased rapidly since 2010. This research aims to compare grasshopper species' abundance, richness, and diversity between several farmland and savannas in Dompu, Sumbawa Island. It was conducted at ten locations in Dompu, Sumbawa Island, and included an ecotone, two post-harvested rice farms, two post-harvested corn farms, a mixed farm, a vegetable farm, and three savannas. Furthermore, samples were taken four times from four plots at each location in the post-harvest period from August to September 2021. Grasshopper sampling was carried out using the sweeping method with an insect net with each plot size of $2 \times 10 \mathrm{~m}^{2}$. A total of 2264 individual grasshoppers belonging to 26 species and four families were collected from all research sites. The dominant species were Alloteratura sp., Trilophidia annulata, Atractomorpha crenulata, Phlaeoba fumosa, Oxya japonica and, Phlaeoba infumata. The greatest grasshopper species richness and diversity were found in post-harvest rice farms, while the lowest was in the vegetable farm, and most of these species are considered pests. This research shows that the composition of grasshoppers on agricultural land is very similar to that of the adjacent savannah. Hence, monitoring and controlling their presence is necessary by paying attention to savannas as refuge land.
\end{abstract}

Keywords: Agricultural land, Alloteratura, Atractomorpha crenulata, Orthoptera, Trilophidia annulata

\section{INTRODUCTION}

Indonesia is one of the megadiverse countries with diverse animal and plant species. Three out of the seventeen world's mega-diversity countries, Indonesia, Malaysia, and the Philippines, are characterized by high biodiversity and endemism (Kier et al. 2009). The great species richness and diversity in Indonesia is due to its geographical position, located in the border of two important geographical zones in the world, namely the Orientalia zone and the Australian zone, and a large number of islands (Lohman et al. 2011).

Arthropoda contributes to great species diversity. Indonesia is estimated to have over 150,000 species of arthropods, but the actual number of species remains unknown. Arthropods are biotic components that play an important role in the ecosystem (Culliney 2013). Moreover, they contribute to pivotal life processes because these animals are part of most terrestrial food webs. Therefore, the performance of a healthy community is strongly supported by the preservation of arthropods (Mattson 2012).

Southeast Asia is also rich in orthopterans such as grasshoppers (Tan et al. 2017a). Apart from the incomplete understanding of the diversity of orthopedics in Southeast Asia (Tan et al. 2017a), there is a pressing need to examine the ecology of orthoptera in Southeast Asia. Orthoptera (grasshoppers, crickets, and katydids) belong to the largest terrestrial insects group, comprising more than 27,000 described species (Cigliano et al. 2017). Grasshoppers are also important bioindicators among herbivores due to their specific habitat preferences and their sensitivity to changes in their habitat (Cigliano et al. 2011). They play an important role in maintaining the balance of the agroforestry ecosystem. However, some grasshopper species are agricultural pests, leaf eaters, and a small part act as the predators of other insects.

In Indonesia, the group of this species is widespread and widely recognized as pests. In the city of Lampung and Sumba, the Migratory locust (Locusta migratoria manilensis) is known in the local community for destroying crops (Lassa 2017). Grasshoppers, as potential pests, can destroy many types of crops, hence it is necessary to record their biodiversity and activities. Several studies on aspects of grasshopper diversity and abundance have been conducted. Sirin et al. (2010) examined the diversity and abundance of grasshopper species concerning altitude. The result showed the greatest species diversity and abundance at medium and low, high and low altitudes. Meanwhile, Prakoso (2017) examined grasshoppers in agroecosystems of corn and forest stand ecosystems. The research found seven grasshopper species belonging to Tetrigidae, Acrididae, and Pyrgomorphidae consisting of Gesonula mundata (Small Lao rice grasshopper), Oxya hyla (Rice grasshopper), Valanga nigricornis (the Javanese grasshopper), Criotettix robustus (ground-hoppers), 
Miramella alpina (Green mountain grasshopper), Hesperotettix viridis (The snakeweed grasshopper) and Atractomorpha crenulata (The tobacco grasshopper).

In Sumbawa Island, the conversion of forests and savannahs into agricultural land has increased rapidly since 2010 due to the high demand for corn. Research conducted in savannah and extensive cultivation areas shows the importance of agricultural landscape management. A mosaic-like agricultural landscape with savannah areas and extensively managed ruderal areas may preserve the high biodiversity of grasshoppers. However, such mosaic effectiveness strongly depends on extensive agricultural management practices that retain significant amounts of herbaceous growth throughout the year (Kuppler 2015). Research on grasshopper potential as a pest in several postharvest agricultural lands and savanna may provide an overview of the potential of the area around agricultural land as a refuge area, consequently, control measures can be carried out wisely. However, none of these studies were specifically conducted in several spots in Dompu Sumbawa Island. This research aims to analyze variations in the abundance, richness, and diversity of grasshopper species among several farmland and savannas in Dompu Sumbawa Island.

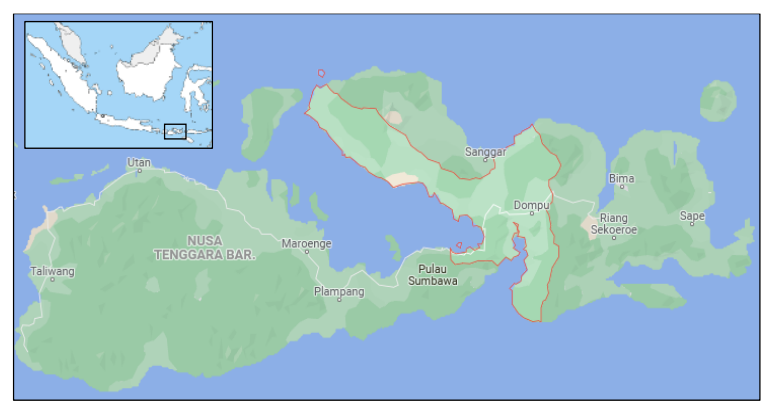

\section{MATERIALS AND METHODS}

This research was conducted in ten locations in Dompu, West Nusa Tenggara, Sumbawa Island, consisted of Note: ECT (Ecotone), MIX (Mixed farm of Carica papaya (papaya) and Zingiber officinale (ginger)), PCF1 (Postharvest corn farm 1), PCF2 (Post-harvest corn farm 2), PRF1 (Post-harvest rice farm 1), PRF2 (Post-harvest rice farm 2), SAV1 (Savana location 1), SAV2 (Savana location 2), SAV3 (Savana location 3), VEG (Vegetable farm) (Figure 1). A more detailed description of the locations is portrayed in Table 1. In each location, samples were taken four times from four plots at each location during a postharvest season from August to September 2021.

The grasshopper sampling was carried out using the sweeping method with an insect flying net with a diameter of $25 \mathrm{~cm}$. The quadrat method, which consists of a predefined sampling surface, was adopted to collect grasshoppers each with a size of $2 \times 10 \mathrm{~m}^{2}$. The samplings were conducted in the morning from 8 a.m. to 11 a.m. under sunny skies and light winds. At each plot, the sampling period took 30-40 minutes. Three groups of field collectors consisted of two persons in each location involved in the sampling to ensure the collection on the same day.

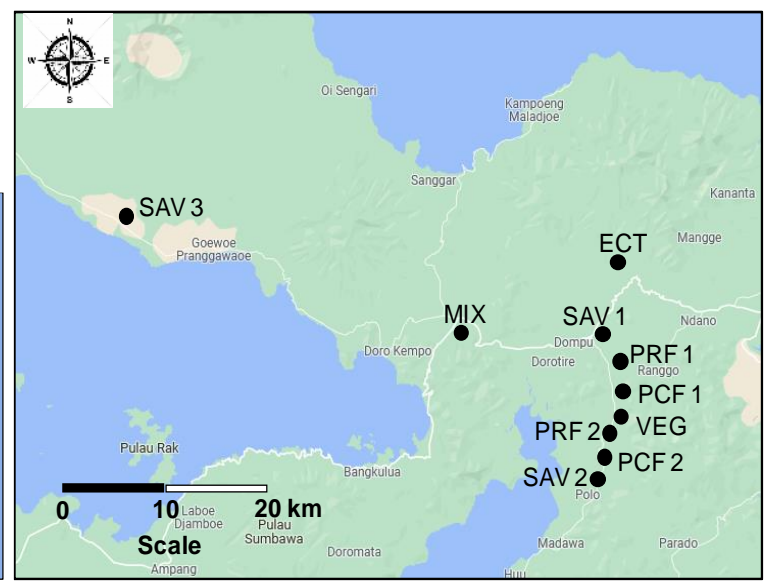

Figure 1. Location of ten research sites in Dompu (Sumbawa Island), West Nusa Tengara, Indonesia. Note: ECT: Ecotone; MIX: Mixed farm of Carica papaya (papaya) and Zingiber officinale (ginger); PCF1: Post-harvest corn farm 1; PCF2: Post-harvest corn farm 2; PRF1: Post-harvest rice farm 1; PRF2: Post-harvest rice farm 2; SAV1: Savana location 1; SAV2: Savana location 2; SAV3: Savana location 3; VEG: Vegetable farm

Table 1. Description of research site

\begin{tabular}{lll}
\hline \multicolumn{1}{c}{ Location } & Abbr. & \\
\hline Ecotone & ECT & Ecotone located between a ricefield land and a stream, dominated by small grass \\
Mixed farm of papaya and ginger & MIX & A mixed land composed of Carica papaya (papaya) and Zingiber officinale (ginger) \\
Post-harvest corn farm 1 & PCF1 & A post corn farm is dominated by medium grass \\
Post-harvest corn farm 2 & PCF2 & A post corn farm is dominated by medium grass \\
Post-harvest rice farm 1 & PRF1 & A post rice farm is dominated by medium grass \\
Post-harvest rice farm 2 & PRF2 & A post rice farm is dominated by medium grass \\
Savana location 1 & SAV1 & A savanna is dominated by cogon grass \\
Savana location 2 & SAV2 & A savanna is dominated by cogon grass \\
Savana location 3 & SAV3 & A savanna is dominated by cogon grass \\
Vegetable farm & VEG & A vegetable farm is composed of Brassicaceae (cabbage and mustard) \\
\hline
\end{tabular}


The obtained grasshopper specimens were put in bottles filled with $70 \%$ ethanol. The specimens identification was carried out at the Laboratory of Animal Diversity, Department of Biology, Faculty of Mathematics and Natural Sciences, Brawijaya University. The specimens were sorted, dried, and then pinned before being identified at the species level. Small specimens were kept in alcohol, while the large ones were stored in an insectarium. The grasshopper specimens were identified based on several identification books (Johnson 2008; Tan 2012; Tan 2017).

The abundance, species richness, and diversity data were analyzed descriptively. Species diversity was analyzed using the Shannon Wiener index (diversity analysis). Similarities in composition between the research site were analyzed using the Bray-Curtis index. Differences between locations were tested by one-way analysis of variance. The results of the data normality test using the Kolmogorov-Smirnov analysis showed that the abundance and diversity data were normally distributed, hence the ANOVA tests were performed, while the species richness data were not normally distributed. After the transformation of the species richness data, further tests indicated the data remained abnormally distributed. Therefore, the test for species richness differences between locations was carried out using a non-parametric test with the Kruskal-Wallis analysis. The posthoc test for parametric analysis by ANOVA was carried out by LSD tests, while that for non-parametric tests was carried out by the Mann-Whitney test. Statistical tests were performed using Excel and SPSS $®$ version 20 (SPSS Inc. Chicago, IL, USA).

\section{RESULTS AND DISCUSSION}

A total of 2264 individual grasshoppers of 26 species and four families were collected from all research sites. The dominant species were Alloteratura sp. (Bush crickets) (16.48\%), Trilophidia annulata (band-winged grasshopper) (15.55\%), Atractomorpha crenulata (Tobacco grasshopper) (10.07\%), Phlaeoba fumosa (Brown grasshopper) (9.14\%), Oxya japonica (the Japanese grasshopper) (8.16\%) and Phlaeoba infumata (silent slant-faced grasshopper) (7.60\%) (Table 1). All dominant species demonstrated a significant abundance between different sites. Alloteratura sp. was found abundantly in a mixed farm, post-harvested corn farm 1 and savanna 3. T. annulata was found abundantly in post-harvest corn farm 1 and savanna 3 . The A. crenulata, $P$. fumosa, and $P$. infumata were also found abundantly in post-harvest corn farms 1 .

Table 1. Number of individual grasshopper species among ten research sites

\begin{tabular}{|c|c|c|c|c|c|c|c|c|c|c|c|c|}
\hline Species & ECT & MIX & PCF1 & PCF2 & PRF1 & PRF2 & SAV1 & SAV2 & SAV3 & VEG & Total & $\%$ \\
\hline Alloteratura sp. & 0 & 60 & 235 & 15 & 0 & 10 & 0 & 53 & 0 & 0 & 373 & 16.48 \\
\hline Trilophidia annulata & 17 & 0 & 117 & 15 & 23 & 9 & 41 & 9 & 113 & 8 & 352 & 15.55 \\
\hline Atractomorpha crenulata & 20 & 42 & 50 & 21 & 24 & 24 & 26 & 21 & 0 & 0 & 228 & 10.07 \\
\hline Phlaeoba fumosa & 16 & 0 & 78 & 25 & 21 & 17 & 24 & 21 & 0 & 5 & 207 & 9.14 \\
\hline Oxya japonica & 0 & 0 & 54 & 7 & 38 & 26 & 24 & 10 & 0 & 14 & 173 & 7.64 \\
\hline Phlaeoba infumata & 0 & 60 & 67 & 23 & 0 & 15 & 0 & 0 & 0 & 7 & 172 & 7.60 \\
\hline Conocephalus maculatus & 38 & 0 & 0 & 10 & 0 & 0 & 0 & 0 & 76 & 0 & 124 & 5.48 \\
\hline Valanga nigricornis & 2 & 10 & 0 & 10 & 0 & 3 & 29 & 0 & 12 & 42 & 108 & 4.77 \\
\hline Eritettix sp. & 0 & 0 & 0 & 7 & 0 & 0 & 0 & 0 & 79 & 0 & 86 & 3.80 \\
\hline Tetrix japonica & 0 & 81 & 0 & 0 & 0 & 0 & 0 & 0 & 0 & 0 & 81 & 3.58 \\
\hline Oxya chinensis & 3 & 45 & 0 & 0 & 0 & 0 & 0 & 0 & 0 & 0 & 48 & 2.12 \\
\hline Tettigidea lateralis & 0 & 0 & 0 & 0 & 0 & 0 & 0 & 0 & 45 & 0 & 45 & 1.99 \\
\hline Locusta migratoria & 0 & 0 & 18 & 5 & 0 & 3 & 0 & 0 & 0 & 15 & 41 & 1.81 \\
\hline Phaesticus insularis & 0 & 0 & 34 & 0 & 0 & 0 & 0 & 0 & 0 & 0 & 34 & 1.50 \\
\hline Phlaeoba antenna & 0 & 0 & 30 & 0 & 0 & 0 & 0 & 0 & 0 & 0 & 30 & 1.33 \\
\hline Oxya hyla & 0 & 0 & 0 & 14 & 0 & 12 & 0 & 0 & 0 & 0 & 26 & 1.15 \\
\hline Achurum carinatum & 0 & 0 & 0 & 0 & 10 & 0 & 15 & 0 & 0 & 0 & 25 & 1.10 \\
\hline Gesonula mudata & 4 & 0 & 0 & 1 & 0 & 0 & 0 & 17 & 0 & 1 & 23 & 1.02 \\
\hline Stenocatantops splendens & 0 & 0 & 0 & 12 & 0 & 1 & 0 & 7 & 0 & 0 & 20 & 0.88 \\
\hline Atractomorpha similis & 6 & 0 & 0 & 0 & 0 & 5 & 0 & 4 & 0 & 0 & 15 & 0.66 \\
\hline Acrida turrita & 2 & 0 & 0 & 0 & 7 & 0 & 2 & 0 & 0 & 0 & 11 & 0.49 \\
\hline Apalacris varicornis & 0 & 0 & 0 & 0 & 0 & 0 & 0 & 7 & 0 & 0 & 7 & 0.31 \\
\hline Euparatettix sp. & 0 & 0 & 0 & 0 & 0 & 0 & 7 & 0 & 0 & 0 & 7 & 0.31 \\
\hline Euconocephalus sp. & 0 & 0 & 0 & 3 & 0 & 0 & 0 & 3 & 0 & 0 & 6 & 0.27 \\
\hline Phaneroptera elongata & 0 & 0 & 0 & 4 & 0 & 0 & 0 & 2 & 0 & 0 & 6 & 0.27 \\
\hline Pseudorhynchus lessonii & 0 & 0 & 0 & 6 & 0 & 0 & 0 & 0 & 0 & 0 & 6 & 0.27 \\
\hline Grand Total & 108 & 298 & 683 & 179 & 123 & 127 & 168 & 161 & 325 & 92 & 2264 & 100.00 \\
\hline
\end{tabular}

Note: ECT: Ecotone; MIX: Mixed farm of Carica papaya (papaya) and Zingiber officinale (ginger); PCF1: Post-harvest corn farm 1; PCF2: Post-harvest corn farm 2; PRF1: Post-harvest rice farm 1, PRF2: Post-harvest rice farm 2; SAV1: Savana location 1; SAV2: Savana location 2; SAV3: Savana location 3; VEG: Vegetable farm 


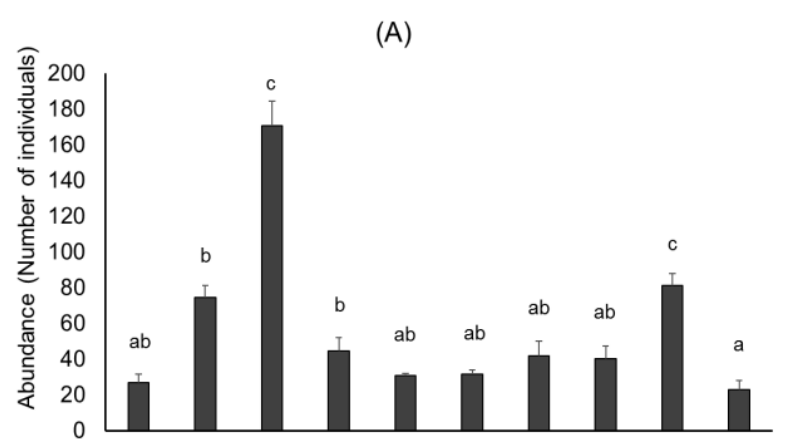

(B)

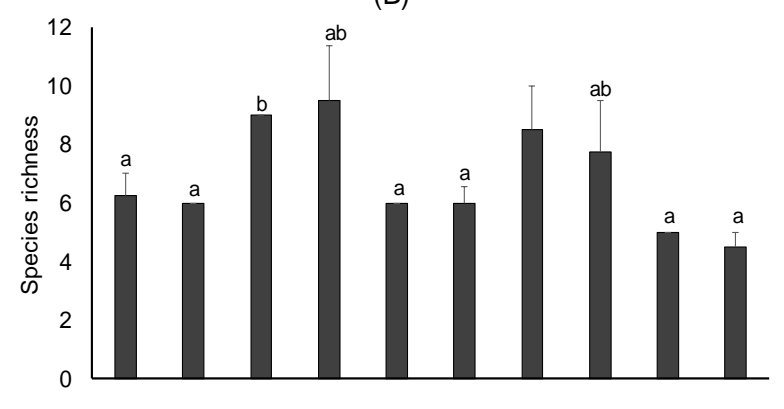

(C)

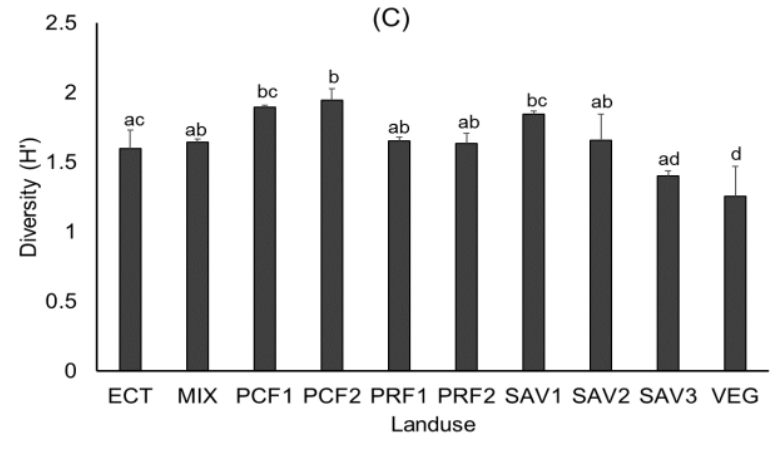

Figure 2. The grasshopper abundance (A), species richness (B), and diversity $(\mathrm{C})$ variation of; among ten research sites in Dompu Sumbawa; the different alphabet above the error bars indicate the significant difference in the mean

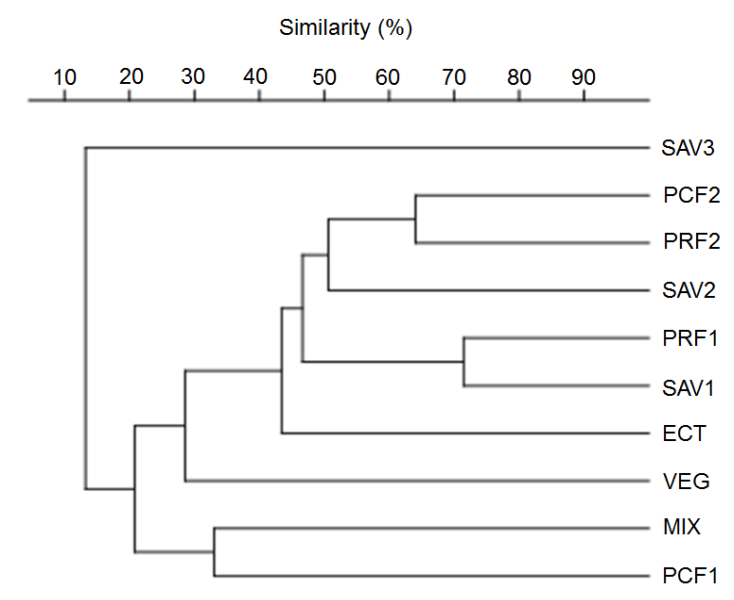

Note: $S A V=$ Savanna; $P C F=$ post-harvested corn farm; PRF = post-harvested rice farm; ECT = Ecotone; VEG = vegetable farm; MIX = mixed farm

Figure 3. The similarity of grasshopper compositions among research sites
Out of the ten research sites, the abundance of grasshoppers in post-harvest rice farms 1 (170.75 \pm 13.63$)$ was the highest, while that in the vegetable farm was the lowest $(23 \pm 4.90)$. The results of statistical analysis showed that the differences in grasshopper abundance between locations were significant $(\mathrm{F}=40.43 ; \mathrm{P}<0.001)$, the posthoc test results are shown in the graph (Figure 2A). The greatest grasshopper species richness was found in post-harvest rice farm $1(9.50 \pm 1.89)$, while the lowest was found in vegetable fam $(4.50 \pm 0.50)$. The results of statistical analysis showed that the differences in the grasshopper richness species among locations were significant (Chi-square $=30.11 ; \mathrm{P}<0.001)$, the results of the posthoc test were shown in the graph (Figure 2B). The same result was obtained in terms of species diversity. The greatest grasshopper species diversity was found in postharvest rice farm $1(1.95 \pm 0.08)$, while the lowest was in vegetable fam $\left(\mathrm{H}^{\prime}=1.25 \pm 0.22\right)$. The results of statistical analysis showed that the differences in grasshopper species diversity between locations were significant $(\mathrm{F}=40.43 .91$; $\mathrm{P}<0.01)$, posthoc test results were shown in the graph (Figure 2.C).

The results of the locust composition similarity test between research areas showed that the degree of similarity in composition between communities ranged in the medium to low range of 20-75 percent. The highest similarity of composition was found in the grasshopper community in PRF 1, savanna 1, which was $71.5 \%$. The ten communities formed two main clusters. The first cluster comprises grasshoppers from PCF2, PRF2, savanna 2, PRF1, savanna 1, ecotone, and vegetable land. The second cluster comprises only two communities in mixed land and PCF1. The composition in savanna three was considered as an outgroup. Internally, group one can be further divided into two sub-groups consisting of the first sub-group consisting of PCF2, PRF2, and savanna 2, while sub-group 2 consists of PRF1 and savanna 1.

\section{Discussion}

Alloteratura sp., T. annulata, A. crenulata, P. fumosa, $O$. japonica and, $P$. infumata were among the most abundant species in this research. Most of these grasshoppers are widespread and highly adapted to environmental changes. Dominant grasshopper species are characterized by highly mobile generalists that tolerate changed landscapes and are mostly geographically widespread (Adu-Acheampong and Samways 2019). Among the species, O. japonica, A. crenulata, and Phlaeoba infumata are common in Asia. Adults and their nymphs are serious pests of economically important grasses, and various crops include rice, millet, sugarcane, maize, wheat, and cabbage (Hassan 2014; Singh 2015). Previous research conducted in Malang East Java showed a similar result due to the great abundance of several species, including Alloteratura sp., P. fumosa, A. crenulata, and $O$. japonica. These species were dominant in several land uses, including agricultural land (Leksono et al. 2020). Research in Baturaden, Central Java, showed that three dominant species, Hesperotettix viridis, G. mundata, and $O$. hyla were included. The other species such as $G$. 
mundata, O. hyla, and V. nigricornis are common in the corn agroecosystems (Zea mays), while Criotettix robustus, M. alpina, $H$. viridis pratensis, and $A$. crenulata are species in plantation forest ecosystems (Prakoso 2017). Another study in Mount Ciremai National Park reported that the dominant species include Gesonia sp., $P$. rustica and Caryanda spuria (short-horned grasshopper), while $O$. cinensis (Chinese rice grasshopper) and Oxya sp. were found in a few individuals.

Research in Punjab, Pakistan showed the abundance of three grasshopper species, including $O$. hyla, O. japonica, and Hieroglyphus banian (Bluish-green rice grasshopper) (Hussain et al. 2017). Highly abundant O. hyla, Tetrix sp., Calliptamus sp., Trilophidia sp. and $H$. banian were also reported in South Gujarat, India (Thakkar et al. 2015). These species are common in rice fields and are regularly observed eating rice leaves; hence these grasshoppers are severe rice pests (Akhtar et al. 2012; Ane and Hussain 2015). Species of the subfamily Oxyinae and Hieroglyphinae such as Acrida exaltata (Belalang menara), O. hyla, and Acrida gigantea (Belalang menara besar) were reported as significant pests of the paddy crop. Meanwhile, the large-sized grasshoppers such as Hieroglyphus sp. Choreodocus sp., L. migratoria, and Gastrimargus africanus (The common yellow-winged grasshopper chidyamamina) are usually found in large grasses or in bushes near agricultural and non-agricultural areas, which were less disturbed by humans. They mainly damage leaves by chewing angular holes with their mandibles (Sultana et al. 2019). The O. nitidula and Acrida sp. are reported to be pests of vegetables in East Uttar Prades, India (Yadaf et al. 2015).

The $T$. annulata is geographically widespread over a steep climate gradient from the cold and temperate north region to the tropical climate of southern China. These distributions provide the opportunity to examine the influence of the environmental clines on intraspecific morphological variation. The genus Trilophidia comprises five species, whose habitats include saturated grasslands, grassland savannas, irrigated areas, and sparse vegetation areas, which are largely restricted to the Ethiopian and Oriental Regions. Out of these five species, T. annulata is the only widespread species distributed over the Oriental Region from West Pakistan to North Borneo and the Palearctic Region of Mongolia, China, Korea, and Japan (Bai et al. 2016).

In this research, $V$. nigricornis were found in several locations, including savannas and a vegetable farm where Brassicaceae was cultivated. During the investigation of the insect diversity on watermelon (Citrullus lanatus) conducted in Cilacap, Central Java, a high abundance of $A$. crenulata and $V$. nigricornis was found. In India and Malaysia, these species were identified as pests (Lee 2013; Singh 2015).

This research showed that there was a relationship between cultivated land and savanna, as shown by the level of community similarity between locations. During the post-harvest, the grasshopper community of the savannah belongs to the same group as that of the rice or maize farms. The similarity analysis shows that all species in post-harvested rice field one are found in savanna 1, nine out of the 11 species in post-harvested rice field two are found in savanna 2. In contrast, eight of 17 species from post-harvested corn farms two are found in savanna 2. This indicates the role of the savanna as a refuge area when their main food is unavailable. Therefore, this research suggests that farmers must pay attention to species that act as pests, attacking crops.

Several recommendations can be made to farmers. First, the manipulation of the soil environment by increasing the Nitrogen content of the soil. This is supported by previous research in the agricultural region of West-Central Senegal. Land use is influenced by the abundance and distribution of grasshoppers, especially Oedaleus senegalensis, likely through soil-plant interactions. The $O$. senegalensis abundance was negatively correlated with plant Nitrogen (Word et al. 2019) because this species prefers low Nitrogen environments (Cease et al. 2015). Second, increasing crop diversity through a mixed planting system. This research shows the low similarity in the composition of a grasshopper on soils of mixed plants with their compositions in other locations. Subsequently, the abundance and diversity of mixed planting grasshoppers are low. Another research reported that high crop diversity could significantly suppress damage of oligophagous pests such as cereal aphids, rice stem borers, and corn borers while having no effects on polyphagous pests such as cotton bollworms and armyworms (Sheng et al. 2017). Third, maintain the presence of natural enemies such as praying mantis. This research reported the presence of Hierodula patellifera and $H$. vitrea (praying mantis) in a small population in the savanna (SAV 3). Efforts to preserve the natural enemies of grasshoppers are pivotal activities.

The abundance and species diversity of grasshoppers varied depending on land use. The abundance of grasshoppers in post-harvest rice farm 1 was the highest, while it was lowest in the vegetable farm. The highest grasshopper species richness and diversity were found in post-harvest rice farm 1, while the lowest was found in the vegetable farm. Subsequently, there was a moderate similarity between the grasshopper compositions in postharvested rice and corn farmlands with those in savannas, indicating the role of the savanna as the refuge area.

\section{ACKNOWLEDGEMENTS}

The authors express profound gratitude to the Rector and Dean of Faculty of Mathematics and Natural Sciences, Universitas Brawijaya, Malang, Indonesia. This research was funded by Professor and Senior Lecture Grant of Universitas Brawijaya.

\section{REFERENCES}

Adu-Acheampong S, Samways MJ. 2019. Traits and land transformation change the fortunes of grasshopper generalists vs. specialists in a biodiversity hotspot. Biosyst Divers 27: 26-32. DOI: 10.15421/011904. 
Akhtar MH, Usmani MK, Nayeem MR, Kumar H. 2012. Species diversity and abundance of Grasshopper fauna (Orthoptera) in rice ecosystem. Ann Biol Res 3 (5): 2190-2193.

Bai Y, Dong JJ, Guan DL, Xie JY, Xu SQ. 2016. Geographic variation in wing size and shape of the grasshopper Trilophidia annulata (Orthoptera: Oedipodidae): Morphological trait variations follow an ecogeographical rule. Sci Rep 6: 32680. DOI: 10.1038/srep32680.

Cease AJ, Elser JJ, Fenichel EP, Hadrich JC, Harrison JF, Robinson BE 2015. Living with locusts: connecting soil nitrogen, locust outbreaks, livelihoods, and livestock markets. Biol Sci 65: 551-558. DOI 10.1093/biosci/biv048.

Cigliano MM, Braun H, Eades DC, Otte D. 2017. Orthoptera species file online. Version 5 (5.0). http: //orthoptera.speciesfile.org.

Cigliano MM, Pocco ME. 2011. Grasshoppers of the Andes: New Melanoplinae and Gomphocerinae taxa (Insecta, Orthoptera Acrididae) from Huascarán National Park and Callejón de Huaylas, Ancash, Peru. Zoosystema 36: 523-544. DOI: 10.5252/z2011n4a5.

Culliney TW. 2013. Role of arthropods in maintaining soil fertility. Fla Entomol 96: 235-244. DOI: 10.3390/agriculture3040629.

Hassan ME. 2014. Chromo-ecological studies of two short horn Grasshoppers, Phlaeoba infumata Brunner and Oedaleus abruptus. Thunberg (Orthoptera: Acrididae). Intl J Fauna Biol 1 (5): 69-79.

Hussain M, Akbar R, Malik MF, Kazam SN, Zainab T. 2017. Diversity, distribution and seasonal variations of grasshopper populations in Sialkot, Punjab, Pakistan. Pure Appl Biol 6 (4): 1372-1381. DOI: 10.19045/bspab

Johnson DL. 2008. Grasshopper Identification and Control methods to Protect Crops and the Environment. Pulse Canada and Saskatchewan Agriculture and Food, Canada

Kier G, Kreft H, Lee TM, Jetz W, Ibisch PL, Nowicki C, Jens MJ, Barthlott W. 2009. A global assessment of endemism and species richness across island and mainland regions. Proc Natl Acad Sci 106: 9322-9327. DOI: 10.1073/pnas.0810306106.

Kuppler J, Fricke J, Hemp C, Steffan-Dewenter I, Peters MK. 2015 Conversion of savannah habitats to small-scale agriculture affects grasshopper communities at Mt. Kilimanjaro, Tanzania. J Insect Conserv 19: 509-518. DOI: 10.1007/s10841-015-9772-7.

Lassa JA. 2017. The Return of Locust Outbreak in Sumba, Indonesia: A Rapid Situational Analysis. Working Paper\# 17, Institute of Resource Governance and Social Change (IRGSC), Kupang.

Lee CY. 2013. Urban Forest Insect Pests and Their Management in Malaysia. International Symposium on Forest Health Management. 111

Leksono AS, Yanuwiadi B, Afandhi A, Farhan M, Zairina A. 2020. The abundance and diversity of grasshopper communities in relation to elevation and land use in Malang, Indonesia. Biodiversitas 21 (12): 5614-5620. DOI: 10.13057/biodiv/d211206

Lohman DJ, de Bruyn M, Page T, von Rintelen K, Hall R, Ng PKL, Shih HT, Carvalho GR, von Rintelen T. 2011. Biogeography of the IndoAustralian Archipelago. Ann Rev Ecol Evol Syst 42: 205-226. DOI: 10.1146/annurev-ecolsys-102710-145001.

Mattson WJ. 2012. The Role of Arthropods in Forest Ecosystems. Springer-Verlag, Nederland.

Noor UA, Hussain M. 2015. Diversity of insect pests in major rice growing areas of the world. J Entomol Zool Stud 4: 36-41.

Prakoso B. 2017. Biodiversitas belalang (Acrididae: ordo Orthoptera) pada agroekosistem (Zea mays L.) dan ekosistem hutan tanaman di Kebun Raya Baturaden, Banyumas. Biosfera 34 (2): 80-88. DOI: 10.20884/1.mib.2017.34.2.490. [Indonesian]

Sheng J, Gao F, Andile M, Wang L, Sandhu HS, Ouyang F, Zhao ZH. 2017. Crop diversity and land simplification effects on pest damage in Northern China. Ann Entomol Soc Am 110 (1): 91-96. DOI: 10.1093/aesa/saw058.

Singh YR, Dharmendra K, Umesh S, Singh D K. 2017. Insect-pests complex of cabbage in eastern Uttar Pradesh. Veg Sci 42 (2): 90-92.

Sirin D, Eren O, Çiplak B. 2010. Grasshopper diversity and abundance in relation to elevation and vegetation from a snapshot in Mediterranean Anatolia: Role of latitudinal position in altitudinal differences. J Nat Hist 44 (5): 1343-1363. DOI: 10.1080/00222930903528214.

Sultana R, Soomro N, Wagan MS. 2019. Description of new species of Oxya from Pakistan with comparison to a close ally (Oxyinae: Acrididae: Orthoptera). Pakistan J Zool 52: 1871-1876. DOI: 10.17582/journal.pjz/20190212100223.

Tan MK, Choi J, Shankar N. 2017 Trends in new species discovery of Orthoptera (Insecta) from Southeast Asia. Zootaxa 4238: 127-134. DOI: 10.11646/zootaxa.4238.1.10.

Tan MK. 2012. Orthoptera in the Bukit Timah and Central Catchment Nature Reserves (Part 1): Suborder Caelifera. Raffles Museum of Biodiversity Research, National University Singapore, Singapore.

Tan MK. 2017. Orthoptera in the Bukit Timah and Central Catchment Nature Reserves (Part 2): Suborder Ensifera. Raffles Museum of Biodiversity Research, National University Singapore, Singapore.

Thakkar B, Parmar S, Parikh PH. 2015. Study on diversity of orthoptera fauna in South Gujarat, India. Intl J Pure Appl Zool 3 (4): 368-374.

Word M, Hall S, Robinson B, Manneh B, Beye A, Cease A. 2019. Soiltargeted interventions could alleviate locust and grasshopper pest pressure in West Africa. Sci Total Environ 663: 632-643. DOI: 10.1016/j.scitotenv.2019.01.313. 